\title{
Downregulation of microRNA-320a inhibits proliferation and induces apoptosis of retinoblastoma cells via targeting TUSC3
}

\author{
LI KONG $^{1}$, YANG SUN $^{1}$, MAOSHENG CHEN $^{1}$, YAN DAI $^{2}$ and ZHEN LIU $^{1}$ \\ ${ }^{1}$ Department of Ophthalmology, Chongqing Aier Eye Hospital, Chongqing 400020; \\ ${ }^{2}$ Department of Ophthalmology, Mianyang Central Hospital, Mianyang, Sichuan 621000, P.R. China
}

Received January 19, 2020; Accepted May 20, 2020

DOI: $10.3892 /$ etm.2020.9137

\begin{abstract}
MicroRNA (miR)-320a is specific to vertebrates and has been indicated to serve a role in a number of cancer types, such as gastric, colorectal, pancreatic and ovarian cancer. miR-320a has been reported to be expressed at high levels in retinoblastoma tissues; however its role and mechanism of function in retinoblastoma remain to be elucidated. The aim of the present study was to investigate the role of miR-320a in retinoblastoma cells and the underlying mechanisms. The expression of miR-320a in retinoblastoma cell lines Y79 and WERI-Rb-1, and normal human retinal pigment epithelial cell line ARPE-19 was examined via reverse transcription-quantitative PCR (RT-qPCR). TargetScan bioinformatics analysis and dual-luciferase reporter assay were used to predict and reveal the target gene of miR-320a. Target gene expression was detected via RT-qPCR in retinoblastoma cell lines and ARPE-19 cells. Subsequently, gain- or loss-of-function experiments for miR-320a and tumor suppressor candidate 3 (TUSC3) were performed to study the role of miR-320a/TUSC3 in retinoblastoma cells. Cell viability and apoptosis were assessed via MTT and flow cytometry analysis, respectively. Compared with ARPE-19 cells, miR-320a was prominently expressed in retinoblastoma cell lines. TUSC3 was predicted to be a target gene of miR-320a. Compared with ARPE-19 cells, the expression of TUSC3 in retinoblastoma cell lines was reduced. The results of MTT and flow cytometry analysis revealed that overexpression of TUSC3 reduced the viability of retinoblastoma cells and induced apoptosis. Additional analysis indicated that miR-320a inhibitor enhanced the expression of the target gene TUSC3, thereby inhibiting retinoblastoma cell viability and inducing apoptosis. The effects of miR-320a inhibitor on retinoblastoma cells were inhibited by TUSC3-short hairpin RNA. miR-320a regulated the viability and apoptosis of retinoblastoma cells via targeting TUSC3. Therefore, the present
\end{abstract}

Correspondence to: Mr. Zhen Liu, Department of Ophthalmology, Chongqing Aier Eye Hospital, 2 Huatang Road, Jiangbei, Chongqing 400020, P.R. China

E-mail: liuzhen14533@163.com

Key words: retinoblastoma, microRNA-320a, tumor suppressor candidate 3 , apoptosis, proliferation study provided a reference for investigating a potential target for the clinical treatment of retinoblastoma.

\section{Introduction}

Retinoblastoma (RB), which is a common and harmful intraocular malignant tumor in children that threatens life (1). $\mathrm{RB}$ incidence is between $1 / 15,000$ and $1 / 20,000$, and is more common in infants and young children, with the majority of cases occurring before the age of six (1). Chemical volume reduction is one of the principal methods of conservative treatment. Local treatment mainly includes laser photocoagulation, transpupillary thermotherapy, photodynamic therapy, cryotherapy and scleral application radiotherapy (2). However, the aforementioned methods lack specificity, and exhibit destructive injuries, low safety, serious systemic and/or local adverse effects and other problems, such as tumor implantation and induction of secondary malignant tumors (2). With the development of tumor molecular biology and genetic engineering technology, coupled with the anatomical advantages of eyeballs as target tissues in the field of RB therapy, gene therapy, as a new type of biological therapy, has demonstrated good application prospects $(3,4)$.

Tumor suppressor candidate 3 (TUSC3) is located on chromosome $8 \mathrm{p} 22$, and is widely expressed in human tissues, such as the brain, heart, lung and liver (5-8). Due to its decreased expression in tumor cells such as colon, breast, liver, pancreatic and rectal cancer, TUSC3 is considered to be a tumor suppressor gene (9-14). TUSC3 is an intrinsic membrane protein that catalyzes the process of endoplasmic reticulum $\mathrm{N}$-glycosylation, which is a major post-translational modification mechanism in cells, and serves a critical role in the folding, regulation and stabilization of proteins (15). Insufficient glycosylation has been indicated to cause endoplasmic reticulum stress, result in genomic damage mutations and cause cancer (16-18). Silencing TUSC3 in prostate and ovarian cancer has been revealed to promote tumor cell growth, metastasis and invasiveness $(7,8)$. Concurrently, the low expression of TUSC 3 in cancer cells may indicate a poor prognosis and a higher possibility of metastasis $(6,19-22)$. TUSC 3 has been indicated to serve a role in a number of malignant tumors including prostate cancer, ovarian cancer, lung cancer and glioma. Therefore, the expression and role of TUSC 3 in retinoblastoma cells requires additional elucidation. 
MicroRNAs (miRs/miRNAs), which are a class of small endogenous non-coding RNAs that are $\sim 22$ nucleotides in length, regulate gene expression at the post-transcriptional level via binding to the 3 '-untranslated region (3'-UTR) of target mRNAs (23-25). miRNAs have been identified to serve critical roles in regulating cell proliferation, differentiation and apoptosis (26-28). A number of studies have indicated the role of miRNAs in tumors $(29,30)$. miR-320a, which is an extensively studied miRNA, has been reported to serve a critical role in diabetic retinopathy (31) and atherosclerosis (32). Moreover, miR-320a has been investigated in several types of cancer, such as lung cancer (33), papillary thyroid cancer (34), osteosarcoma (35) and hepatocellular carcinoma (36). Moreover, miR-320a has been reported to be upregulated in retinoblastoma tissues (37); however its role and mechanism in retinoblastoma remain to be elucidated.

Bioinformatics analysis revealed direct interaction sites between miR-320a and TUSC3. Therefore, it was hypothesized that miR-320a may serve a role in retinoblastoma cells via regulating TUSC 3 . The aim of the present study was to explore the role of miR-320 in retinoblastoma cells and analyze its molecular mechanism of function to provide novel insights for the treatment of retinoblastoma.

\section{Materials and methods}

Cell culture. The human normal retinal vascular endothelial cell line ARPE-19 and the retinoblastoma cell lines Y79 and WERI-Rb-1 were obtained from American Type Culture Collection. The cells were cultured in DMEM (Gibco; Thermo Fisher Scientific, Inc.) supplemented with 10\% FBS (Gibco; Thermo Fisher Scientific, Inc.) and 1\% penicillin/streptomycin in a humidified incubator at $37^{\circ} \mathrm{C}$ with $5 \% \mathrm{CO}_{2}$.

Reverse transcription-quantitative PCR (RT-qPCR). RNA extraction from ARPE-19, Y79 and WERI-Rb-1 cells was performed using TRIzol ${ }^{\circledast}$ reagent (Invitrogen; Thermo Fisher Scientific, Inc.) according to the manufacturer's instructions. cDNA was reverse transcribed from RNA using the HiScript II Q RT SuperMix (Vazyme Biotech Co., Ltd.). The following temperature conditions for RT were as follows: $70^{\circ} \mathrm{C}$ for $5 \mathrm{~min}$, $37^{\circ} \mathrm{C}$ for $5 \mathrm{~min}$ and $42^{\circ} \mathrm{C}$ for $60 \mathrm{~min}$. Subsequently, qPCR was performed using ChamQ Universal SYBR ${ }^{\circledR}$ qPCR Master Mix (Vazyme Biotech Co., Ltd.) according to the manufacturer's instructions. The following thermocycling conditions were used for the qPCR: Initial denaturation at $95^{\circ} \mathrm{C}$ for $10 \mathrm{~min}$; 40 cycles of denaturation at $95^{\circ} \mathrm{C}$ for $10 \mathrm{sec}$, annealing at $60^{\circ} \mathrm{C}$ for $20 \mathrm{sec}$ and extension at $72^{\circ} \mathrm{C}$ for $34 \mathrm{sec}$. GAPDH for mRNA and U6 for miRNA were used as the internal controls. The primer sequences used for the PCR were listed as follows: GAPDH forward, 5'-CTTTGGTATCGTGGAAGGACTC-3' and reverse, 5'-GTAGAGGCAGGGATGATGTTCT-3'; U6 forward, 5'-GCT TCGGCAGCACATATACTAAAAT-3' and reverse, 5'-CGC TTCACGAATTTGCGTGTCAT-3'; miR-320a forward, 5'-GTT GGATCCGGCGTTTCCTTCCGACATG-3' and reverse, 5'-GCTGAATTCGTCCACTGCGGCTGTTCC-3'; TUSC3 forward, 5'-GGCTCAGTTTGTGGCAGAATC-3' and reverse, 5'-CATCGCCTTTCGAAGTTGCT-3'. The relative gene expression levels were analyzed using the $2^{-\Delta \Delta C q}$ method (38). All experiments were performed in triplicate.

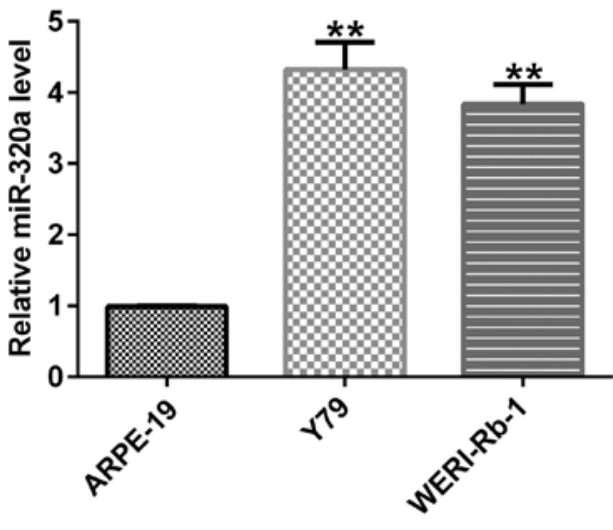

Figure 1. Expression of miR-320a in retinoblastoma cell lines Y79 and WERI-Rb-1. Reverse transcription-quantitative PCR was performed to examine the expression of miR-320a in retinoblastoma cell lines Y79 and WERI-Rb-1 and the normal human retinal pigment human normal retinal vascular endothelial cell line ARPE-19. The data are presented as the mean \pm standard deviation. ${ }^{* *} \mathrm{P}<0.01$ vs. ARPE-19 cells. miR-320a, microRNA-320-a.

Dual-luciferase reporter assay. TargetScan bioinformatics software version 7.2 (www.targetscan.org/vert_72) was used to predict the potential targets of miR-320a. Binding sites between miR-320a and the 3'-untranslated region (3'-UTR) of TUSC 3 were observed. Dual luciferase reporter assay was performed to determine whether miR-320a directly bound to TUSC3. Wild-type (WT) and mutant (MUT) 3'-UTR of TUSC 3 were cloned into pmiR-RB-Report ${ }^{\mathrm{TM}}$ dual luciferase reporter vector (Guangzhou RiboBio Co., Ltd.) according to the manufacturer's instructions. 293 T cells (American Type Culture Collection) were co-transfected with WT-TUSC 3 or MUT-TUSC 3 and $100 \mathrm{nM}$ miR-320a mimic (5'-AAAAGC UGGGUUGAGAGGGCGA-3'; 3'-UUUUCGACCCAACUC UCCCGCU-5'; Guangzhou RiboBio Co.,Ltd.) or $100 \mathrm{nM} \mathrm{mimic}$ control (5'-UUCUCCGAACGUGUCACGUTT-3'; 3'-TTA AGAGGCUUGCACAGUGCA-5'; Guangzhou RiboBio Co., Ltd.) using Lipofectamine ${ }^{\circledR} 2000$ (Invitrogen; Thermo Fisher Scientific, Inc.) at $37^{\circ} \mathrm{C}$ for $48 \mathrm{~h}$. At $48 \mathrm{~h}$ after transfection, luciferase activity was determined using the Dual-luciferase ${ }^{\circledR}$ Reporter Assay system (Promega Corporation) and normalized to Renilla luciferase activity.

Cell transfection. $1 \mu \mathrm{g}$ TUSC3-plasmid (cat no. sc-405571-ACT; Santa Cruz Biotechnology, Inc.), $1 \mu \mathrm{g}$ control-plasmid (cat no. sc-437275; Santa Cruz Biotechnology, Inc.), $100 \mathrm{nM}$ inhibitor control (5'-UUGUCCUACACCUCACUCCUG-3'; Guangzhou RiboBio Co., Ltd.), 100 nM miR-320a inhibitor (5'-UCGCCCUCUCAACCCAGCUUUU-3'; Guangzhou RiboBio Co., Ltd.), $1 \mu \mathrm{g}$ TUSC3-short hairpin RNA (shRNA; cat no. sc-77535-SH; Santa Cruz Biotechnology, Inc.), $1 \mu \mathrm{g}$ control-shRNA (cat no. sc-108060; Santa Cruz Biotechnology, Inc.), $100 \mathrm{nM}$ miR-320a inhibitor $+1 \mu \mathrm{g}$ control-shRNA and $100 \mathrm{nM}$ miR-320a inhibitor $+1 \mu \mathrm{g}$ TUSC3-shRNA were transfected into Y79 and WERI-Rb-1 cells $\left(5 \times 10^{4}\right.$ cells per well; 24 well plates) using Lipofectamine ${ }^{\circledR} 2000$ reagent (Invitrogen; Thermo Fisher Scientific, Inc.) according to the manufacturer's protocol. Cells without any treatment were used as the control. The transfection efficiency was examined via RT-qPCR following $48 \mathrm{~h}$ of transfection. 

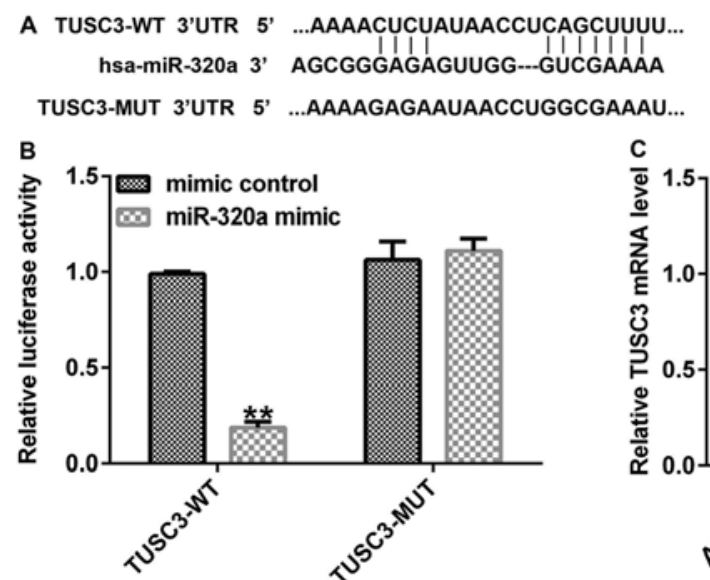

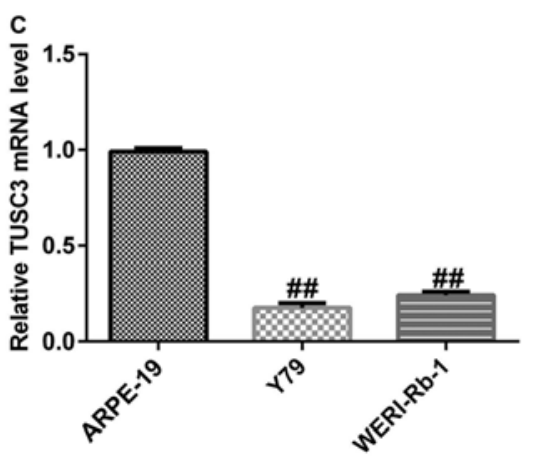

D

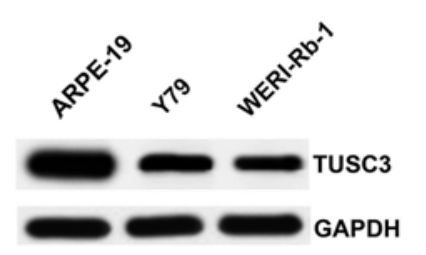

Figure 2. Target gene of miR-320a and its expression in retinoblastoma cell lines. (A) Predicted binding sites between the WT UTR of TUSC3 and miR-320a via TargetScan. (B) Dual-luciferase assay was performed to verify the target gene of miR-320a. (C) The mRNA and (D) the protein expression of TUSC3 in retinoblastoma cells Y79 and WERI-Rb-1 and the normal human retinal pigment human normal retinal vascular endothelial cell line ARPE-19 was assessed via reverse transcription-quantitative PCR and western blot analysis. The data are presented as the mean \pm standard deviation. ${ }^{* *} \mathrm{P}<0.01$ vs. mimic control group; " ${ }^{\#} \mathrm{P}<0.01$ vs. ARPE-19 cells. miR-320a, microRNA-320-a; TUSC3, tumor suppressor candidate 3; WT, wild-type; MUT, mutant.

MTT assay. Y79 and WERI-Rb-1 cells were seeded in 96-well plates $\left(5 \times 10^{4}\right.$ cells per well) and transfected with TUSC3-plasmid, control-plasmid, miR-320a inhibitor, control inhibitor, miR-320a inhibitor + control-shRNA or miR-320a inhibitor + TUSC3-shRNA for $48 \mathrm{~h}$. Subsequently, $20 \mu \mathrm{l} \mathrm{MTT}$ solution (5 g/l; Sigma-Aldrich; Merck KGaA) was added to each well. The plates were incubated at $37^{\circ} \mathrm{C}$ with $5 \% \mathrm{CO}_{2}$ for $4 \mathrm{~h}$. The culture medium was then discarded and $150 \mu \mathrm{l}$ DMSO (Beyotime Institute of Biotechnology) was added to each well. The plates were gently agitated at $37^{\circ} \mathrm{C}$ for $10 \mathrm{~min}$. The optical density was measured at a wavelength of $490 \mathrm{~nm}$ using a multifunctional plate reader (BD Biosciences).

Flow cytometry analysis. At $48 \mathrm{~h}$ after transfection, Y79 and WERI-Rb-1 cells $\left(10^{6}\right.$ cells $)$ in the log phase were digested with trypsin $(0.25 \%)$ without EDTA at room temperature for $1 \mathrm{~min}$, centrifuged at $1,000 \mathrm{x}$ for $5 \mathrm{~min}$ at $4^{\circ} \mathrm{C}$, and the supernatant was discarded. The cell pellet was washed twice with pre-chilled PBS and then resuspended in $195 \mu 1$ pre-chilled $1 \mathrm{X}$ Annexin V binding buffer (Annexin V-FITC Cell apoptosis detection kit; Beyotime Institute of Biotechnology). Subsequently, cells were incubated with $5 \mu$ Annexin V-FITC and $10 \mu \mathrm{l}$ propidium iodide for $15 \mathrm{~min}$ at room temperature in the dark. To detect apoptosis, flow cytometry (Beckman Coulter, Inc.) was performed. The data were analyzed using CellQuest $^{\mathrm{TM}}$ v5.1 software (BD Biosciences).

Western blot analysis. The expression of TUSC3 was detected via western blotting. Proteins from ARPE-19, Y79 and WERI-Rb-1 cells were extracted using RIPA lysis buffer (Beyotime Institute of Biotechnology) and protein concentration was measured using a BCA assay kit (Sigma-Aldrich; Merck KGaA) according to the manufacturer's protocol. A total of $40 \mu \mathrm{g}$ proteins/lane were separated using 10\% SDS-PAGE and subsequently transferred to PVDF membranes (EMD Millipore). Following blocking with 5\% skimmed milk for $1 \mathrm{~h}$ at room temperature, the membranes were incubated with primary antibodies for TUSC3 (1:1,000; cat no. ab230520; Abcam) and GAPDH (1:1,000; cat no. ab181602; Abcam) overnight at $4^{\circ} \mathrm{C}$. Subsequently, the membranes were incubated with a corresponding horseradish peroxidase-conjugated secondary antibody (1:2,000; cat. no. 7074; Cell Signaling Technology, Inc.) for $1 \mathrm{~h}$ at room temperature. Protein bands were visualized using ECL Western blotting Detection Reagents (Cytiva).

Statistical analysis. Experiments were repeated in triplicate. Data are presented as the mean \pm standard deviation of three independent experiments. Statistical analysis was performed using GraphPad Prism v5 software (GraphPad Software, Inc.). Statistical differences between multiple groups were analyzed using one-way ANOVA with a Bonferroni post hoc test, and Student's t-test was used for comparison between two groups, as applicable. $\mathrm{P}<0.05$ was considered to indicate a statistically significant difference.

\section{Results}

miR-320a expression in retinoblastoma cell lines. RT-qPCR was performed to examine the expression of miR-320a in retinoblastoma cell lines Y79 and WERI-Rb-1, and human normal retinal vascular endothelial cell line ARPE-19. As demonstrated in Fig. 1, compared with ARPE-19 cells, the expression of miR-320a in retinoblastoma cell lines Y79 and WERI-Rb-1 was upregulated, which is consistent with a previous study on miR-320a (37). These results indicated that miR-320a was expressed at a higher level in retinoblastoma cell lines Y79 and WERI-Rb-1, compared with normal retinal cells.

Target gene of miR-320a. Binding sites between miR-320a and the 3'-UTR of TUSC3 mRNA were predicted via TargetScan (Fig. 2A), which indicated that TUSC3 is a potential target gene of miR-320a. A luciferase reporter assay revealed that miR-320a mimic suppressed the luciferase activity when 293 T cells were co-transfected with a reporter plasmid containing the WT 3'-UTR and miR-320a mimic (Fig. 2B). However, the luciferase activity of the MUT 3'-UTR was not altered. These data indicated that TUSC3 was a direct target of miR-320a. 
A

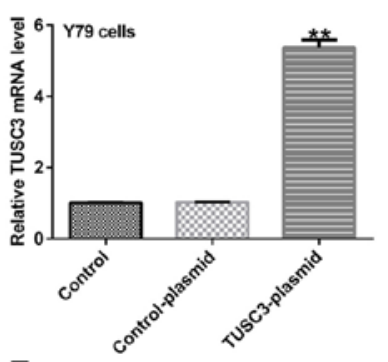

E

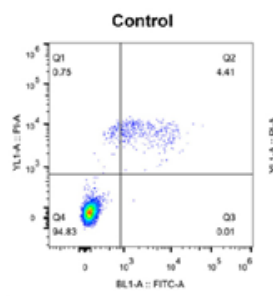

G

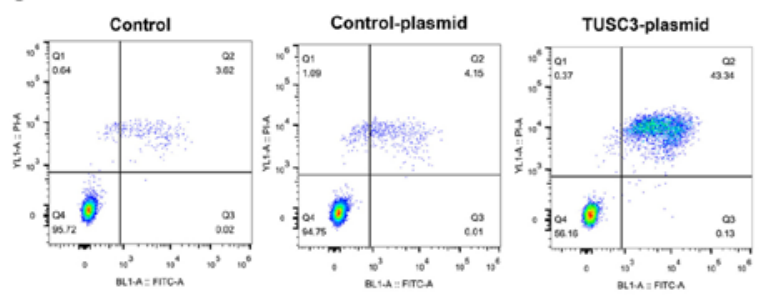

Control-plasmid
C
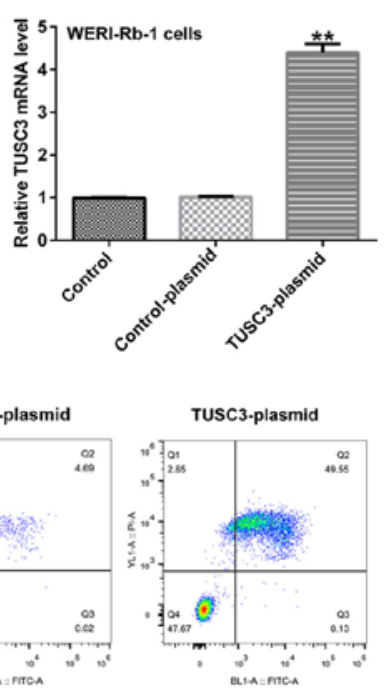

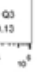

H

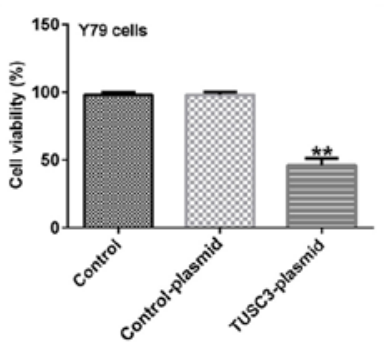

$F$
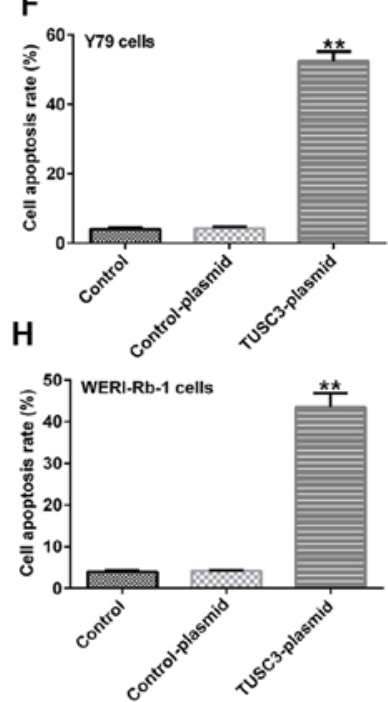

D

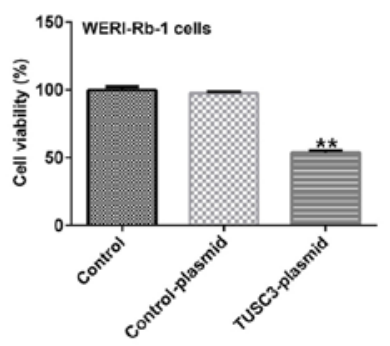

Figure 3. Effect of TUSC3 overexpression on retinoblastoma cell viability and apoptosis. Y79 and WERI-Rb-1 cells were transfected with TUSC3-plasmid and control-plasmid for $48 \mathrm{~h}$. The expression of TUSC3 in (A) Y79 and (B) WERI-Rb-1 cells was examined via reverse transcription-quantitative PCR. The viability of (C) Y79 and (D) WERI-Rb-1 cells was assessed via MTT assay. The apoptosis of (E and F) Y79 and (G and H) WERI-Rb-1 cells was assessed via flow cytometry. The data are presented as the mean \pm standard deviation. ${ }^{* *} \mathrm{P}<0.01$ vs. control-plasmid. TUSC 3 , tumor suppressor candidate 3.

A

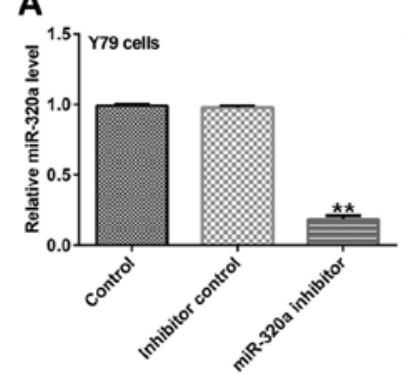

E

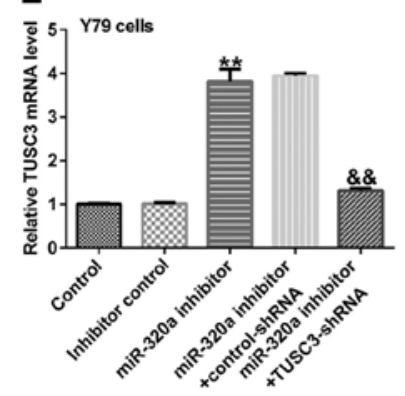

B

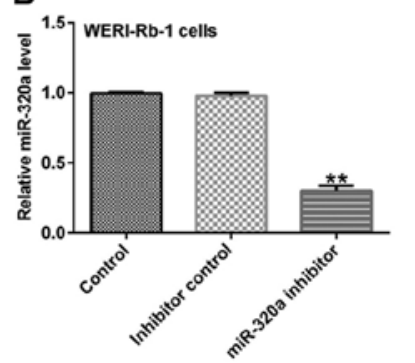

$\mathbf{F}$

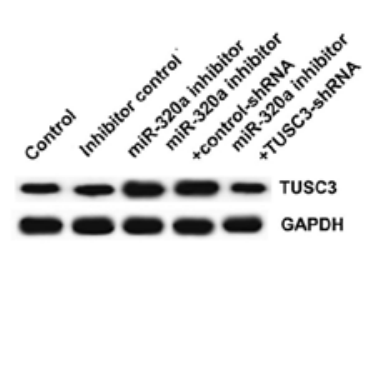

C

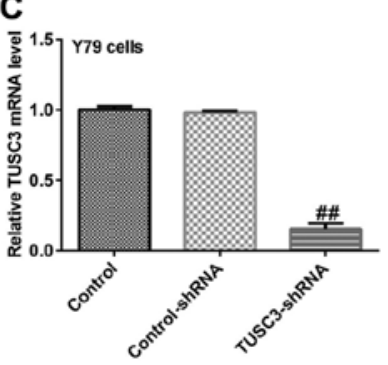

G

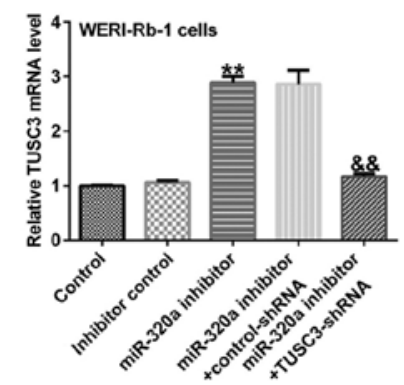

D

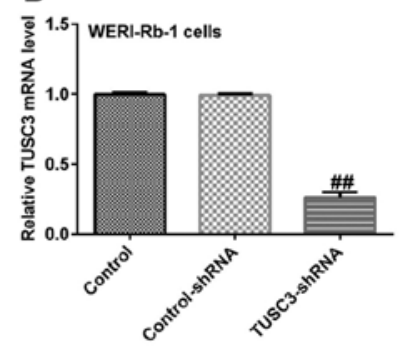

H

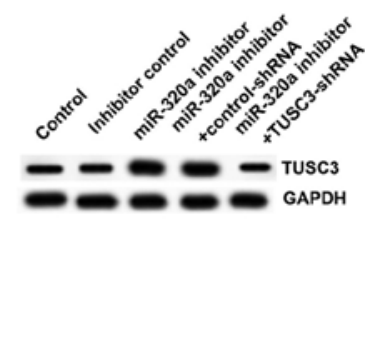

Figure 4. Expression of miR-320a and TUSC3 in transfected cells. Y79 and WERI-Rb-1 cells were transfected with inhibitor control, miR-320a inhibitor, TUSC3-shRNA, control-shRNA, miR-320a inhibitor + control-shRNA or miR-320a inhibitor + TUSC3-shRNA. Expression of miR-320a in (A) Y79 and (B) WERI-Rb-1 cells transfected with inhibitor control or miR-320a inhibitor. TUSC3 mRNA expression in (C) Y79 and (D) WERI-Rb-1 cells transfected with control-shRNA or TUSC3-shRNA. (E) mRNA and (F) protein expression of TUSC3 in Y79 cells transfected with inhibitor control, miR-320a inhibitor, miR-320a inhibitor + control-shRNA or miR-320a inhibitor + TUSC3-shRNA. (G) mRNA and (H) protein expression of TUSC3 in WERI-Rb-1 cells transfected with inhibitor control, miR-320a inhibitor, miR-320a inhibitor + control-shRNA or miR-320a inhibitor + TUSC3-shRNA. The data are presented as the mean \pm standard deviation. ${ }^{* *} \mathrm{P}<0.01$ vs. inhibitor control; ${ }^{\# /} \mathrm{P}<0.01$ vs. control-shRNA; ${ }^{\&} \mathrm{P}<0.01 \mathrm{vs}$. miR-320a inhibitor + control-shRNA. miR-320a, microRNA-320a; TUSC3, tumor suppressor candidate 3; shRNA, short hairpin RNA. 
A

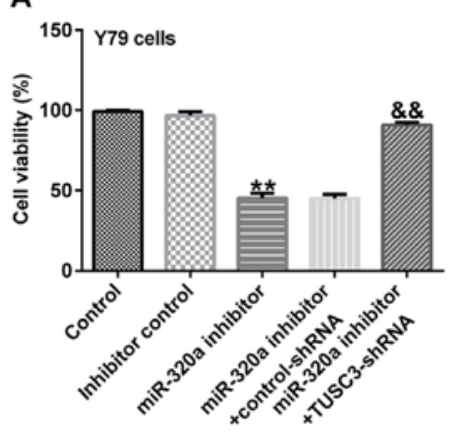

C

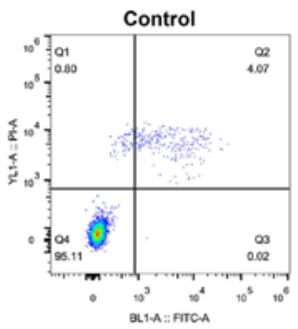

miR-320a inhibitor

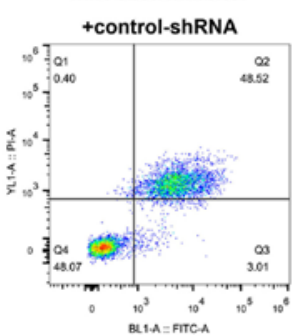

E

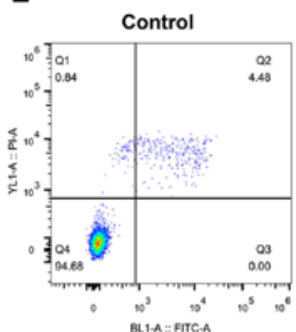

miR-320a inhibitor

+control-shRNA

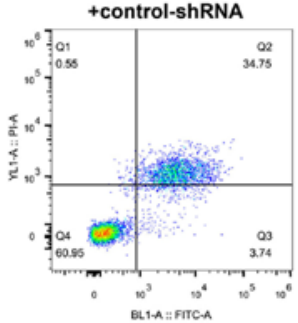

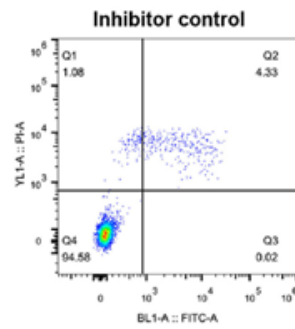

miR-320a inhibitor
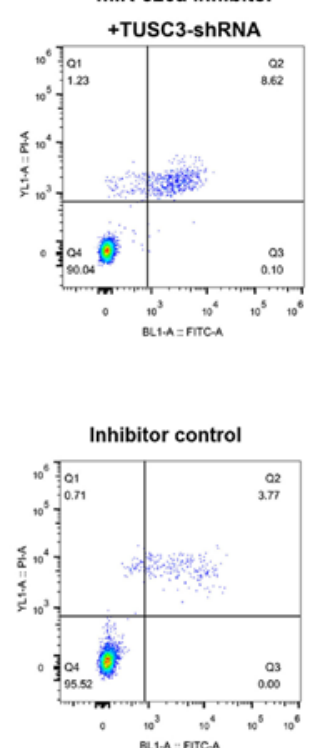

miR-320a inhibitor

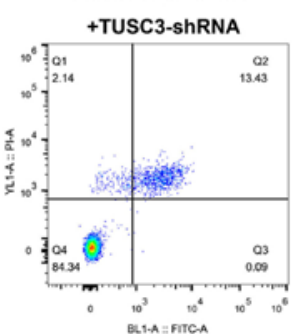

B
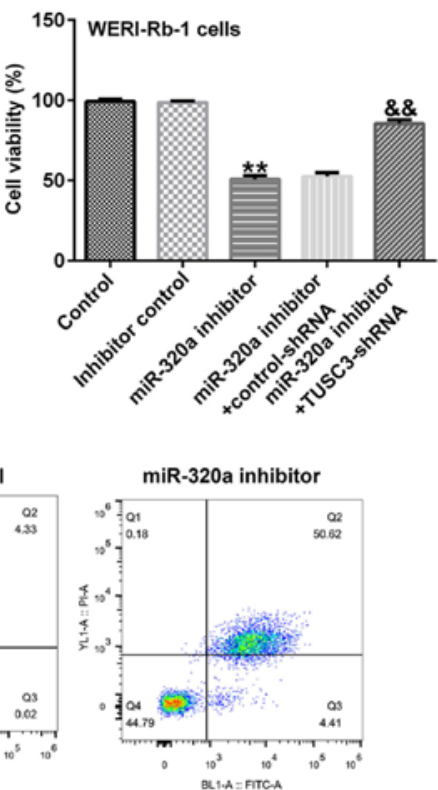

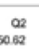
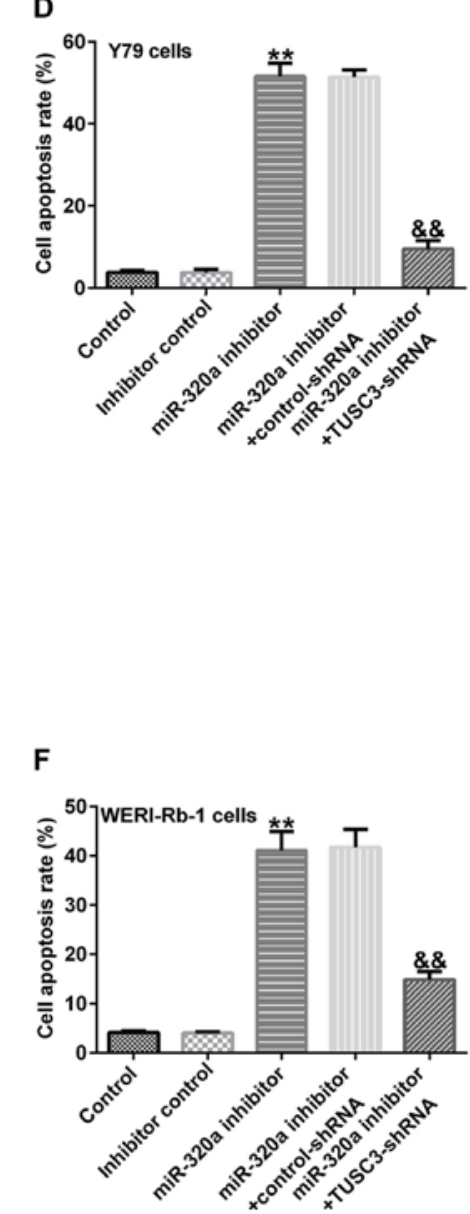

Figure 5. Effect of miR-320a inhibition on cell viability and apoptosis in Y79 and WERI-Rb-1 cells. Y79 and WERI-Rb-1 cells were transfected with inhibitor control, miR-320a inhibitor, miR-320a inhibitor + control-shRNA or miR-320a inhibitor + TUSC3-shRNA for 48 h. Cell viability of (A) Y79 and (B) WERI-Rb-1 cells. Cell apoptosis of (C and D) Y79 and (E and F) WERI-Rb-1 cells. The data are presented as the mean \pm standard deviation. ${ }^{* *} \mathrm{P}<0.01$ vs. inhibitor control; ${ }^{\&} \mathrm{P}<0.01$ vs. miR-320a inhibitor + control-shRNA. miR-320a, microRNA-320a; TUSC3, tumor suppressor candidate 3; shRNA, short hairpin RNA.

The expression of TUSC3 in retinoblastoma cell lines Y79 and WERI-Rb-1 and the human normal retinal vascular endothelial cell line ARPE-19 was examined via RT-qPCR and western blotting. The results indicated that compared with ARPE-19 cells, the mRNA and protein expression of TUSC3 was reduced in both retinoblastoma cell lines (Fig. 2C and D).
Effect of TUSC3 overexpression on retinoblastoma cell viability and apoptosis. Y79 and WERI-Rb-1 cells were transfected with TUSC3-plasmid and control-plasmid. Following $48 \mathrm{~h}$ of transfection, RT-qPCR was performed to assess transfection efficiency. MTT assay and flow cytometry were also performed to assess cell viability and apoptosis, respectively. 
Compared with the control-plasmid group, the mRNA expression of TUSC3 in Y79 and WERI-Rb-1 cells was increased following transfection with TUSC3-plasmid (Fig. 3A and B). Moreover, the viability of Y79 (Fig. 3C) and WERI-Rb-1 (Fig. 3D) cells was reduced, while the apoptotic rates of Y79 (Fig. 3E and F) and WERI-Rb-1 (Fig. 3G and H) cells were increased, compared with the control-plasmid group.

Effect of miR-320a inhibition on retinoblastoma cell viability and apoptosis. Y79 and WERI-Rb-1 cells were transfected with inhibitor control, miR-320a inhibitor, TUSC3-shRNA, control-shRNA, miR-320a inhibitor + control-shRNA or miR-320a inhibitor + TUSC3-shRNA for $48 \mathrm{~h}$. RT-qPCR was performed to assess transfection efficiency.

As presented in Fig. 4A and B, compared with the inhibitor control group, miR-320a inhibitor reduced the expression of miR-320a in Y79 and WERI-Rb-1 cells. Compared with the control-shRNA group, TUSC3-shRNA reduced the mRNA expression of TUSC 3 in Y79 and WERI-Rb-1 cells (Fig. 4C and D). Moreover, miR-320a inhibitor increased the mRNA and protein expression of TUSC 3 in Y79 cells (Fig. 4E and F) and WERI-Rb-1 cells (Fig. 4G and H), compared with the inhibitor control group, while this increase was reversed by TUSC3-shRNA.

Subsequent analysis indicated that compared with the inhibitor control group, miR-320a inhibitor reduced the cell viability (Fig. 5A and B) and induced apoptosis (Fig. 5C-F) in Y79 and WERI-Rb-1 cells, while these alterations were reversed by TUSC3-shRNA.

\section{Discussion}

The potential biomarkers and therapeutic targets of tumors have provided insight into the clinical treatment of retinoblastoma $(39,40)$. In recent years, the relationship between miRNAs and retinoblastoma has been extensively studied $(41,42)$. Different miRNAs have been indicated to exhibit distinct expression levels in diverse tumor tissues, and may exert both oncogenic and antitumor effects $(40,43)$. Gao et al (44) revealed that compared with the placental samples from healthy control subjects, miR-320a expression was enhanced in the placental specimens of patients with pre-eclampsia and excessive miR-320a expression was indicated to suppress the trophoblast invasion; however it did not affect the trophoblast migration or proliferation. Yong et al (45) presented evidence that ectopic expression of DiGeorge syndrome critical region gene 5 inhibited proliferation and migration, and promoted fluorouracil resistance in pancreatic ductal adenocarcinoma cells, while its mechanism of action was associated with miR-320a. The present study focused on the investigation of the role of miR-320a in retinoblastoma cells.

The expression of miR-320a and TUSC 3 in retinoblastoma and their mechanism of action require additional elucidation. The present study was performed based on the results of previous research (37). Consistently with a previous study (37), the results of the present study indicated that miR-320a expression was upregulated in retinoblastoma cells compared with normal retinal cells. TUSC3, which is a well-known tumor suppressor gene, was revealed to be a direct target of miR-320a, and was indicated to be negatively regulated by miR-320a.
Furthermore, the expression of TUSC3 was downregulated in retinoblastoma cells compared with normal retinal cells. Subsequent analyses indicated that TUSC 3 overexpression reduced retinoblastoma cell viability and induced cell apoptosis. Moreover, miR-320a downregulation inhibited the viability of retinoblastoma cells and induced cell apoptosis. The effects of miR-320a inhibitor on retinoblastoma cells were reversed by TUSC3-shRNA. However, apoptosis-related proteins were not examined in the current study, and the efficiency of TUSC 3 knock-down and upregulation were only detected via RT-qPCR. These were the limitations of the current study, and require additional investigation.

In conclusion, the present study demonstrated that in human retinoblastoma cells, inhibition of miR-320a prevented cell growth via targeting TUSC 3 . miR-320a may be a novel potential target for retinoblastoma treatment.

\section{Acknowledgements}

Not applicable.

\section{Funding}

No funding was received.

\section{Availability of data and materials}

The datasets used and/or analyzed during the current study are available from the corresponding author on reasonable request.

\section{Authors' contributions}

LK designed the current study, collected the data, performed statistical analysis, interpreted the data and prepared the manuscript preparation. YS, MC and YD collected the data and performed statistical analysis. ZL designed the current study, collected the data and prepared the manuscript. All authors read and approved the final manuscript.

\section{Ethics approval and consent to participate}

Not applicable.

\section{Patient consent for publication}

Not applicable.

\section{Competing interests}

The authors declare that they have no competing interests.

\section{References}

1. Wong JR, Tucker MA, Kleinerman RA and Devesa SS: Retinoblastoma incidence patterns in the US surveillance, epidemiology, and end results program. JAMA Ophthalmol 132: 478-483, 2014.

2. Riquelam I, Tapia O, Leal P, Sandoval A, Varga MG, Letelier P, Buchegger K, Bizama C, Espinoza JA, Peek RM, et al: miR-101-2, miR-125b-2 and miR-451a act as potential tumor suppressors in gastric cancer through regulation of the PI3K/AKT/mTOR pathway. Cell Oncol (Dordr) 39: 23-33, 2016. 
3. McEvoy JD and Dyer MA: Genetic and epigenetic discoveries in human retinoblastoma. Crit Rev Oncog 20: 217-225, 2015.

4. Gudiseva HV, Berry JL, Polski A, Tummina SJ and O'Brien JM: Next-generation technologies and strategies for the management of retinoblastoma. Genes (Basel) 10: 1032, 2019.

5. Kong L, Zhang P, Li W, Yang Y, Tian Y, Wang X, Chen S, Yang Y, Huang T, Zhao T, et al: KDM1A promotes tumor cell invasion by silencing TIMP3 in non-small cell lung cancer cells. Oncotarget 7 : 27959-27974, 2016

6. Fan X, Zhang X, Shen J, Zhao H, Yu X, Chen Y,Zhuang Z, Deng X, Feng H, Wang Y and Peng L: Decreased TUSC3 promotes pancreatic cancer proliferation, invasion and metastasis. PLoS One 11: e0149028, 2016.

7. Horak P, Tomasich E, Vaňhara $\mathrm{P}$, Kratochvílová K, Anees M, Marhold M, Lemberger CE, Gerschpacher M, Horvat R, Sibilia M, et al: TUSC3 loss alters the ER stress response and accelerates prostate cancer growth in vivo. Sci Rep 4: 3739, 2014.

8. Kratochvílová K, Horak P, Ešner M, Souček K, Pils D, Anees M, Tomasich E, Dráfi F, Jurtíková V, Hampl A, et al: Tumor suppressor candidate 3 (TUSC3) prevents the epithelial-to-mesenchymal transition and inhibits tumor growth by modulating the endoplasmic reticulum stress response in ovarian cancer cells. Int J Cancer 137: 1330-1340, 2015.

9. Li P, Zheng X, Shou K, Niu Y, Jian C, Zhao Y, Yi W, Hu X and $\mathrm{Yu}$ A: The iron chelator Dp44mT suppresses osteosarcoma's proliferation, invasion and migration: In vitro and in vivo. Am J Transl Res 8: 5370-5385, 2016.

10. Li YG, Liang NX, Qin YZ, Ma DJ, Huang CJ, Liu L and Li SQ Effects of RNAi-mediated TUSC3 silencing on radiation-induced autophagy and radiation sensitivity of human lung adenocarcinoma cell line A549 under hypoxic condition. Tumour Biol 37 $16357-16365,2016$

11. Ohno Y, Koyama H, Yoshikawa T, Takenaka D, Seki S, Yui M, Yamagata H, Aoyagi K, Matsumoto S and Sugimura K: Three-way comparison of whole-body MR, coregistered whole-body FDG PET/MR, and Integrated whole-body FDG PET/CT imaging: TNM and stage assessment capability for non-small cell lung cancer patients. Radiology 275: 849-861, 2015.

12. Scagliotti G, Kang JH, Smith D, Rosenberg R, Park K, Kim SW, Su WC, Boyd TE, Richards DA, Novello S, et al: Phase II evaluation of LY2603618, a first-generation CHK1 inhibitor, in combination with pemetrexed in patients with advanced or metastatic non-small cell lung cancer. Invest New Drugs 34: 625-635, 2016.

13. Chung KW, Kim SW and Kim SW: Gene expression profiling of papillary thyroid carcinomas in Korean patients by oligonucleotide microarrays. J Korean Surg Soc 82: 271-280, 2012.

14. Yang L, Chen Y, Cui T, Knösel T, Zhang Q, Albring KF, Huber O and Petersen I: Desmoplakin acts as a tumor suppressor by inhibition of the Wnt/ $\beta$-catenin signaling pathway in human lung cancer. Carcinogenesis 33: 1863-1870, 2012.

15. Yu X, Zhai C, Fan Y, Zhang J, Liang N, Liu F, Cao L, Wang J and Du J: TUSC3: A novel tumour suppressor gene and its functional implications. J Cell Mol Med 21: 1711-1718, 2017.

16. Pils D, Horak P, Vanhara P, Anees M,Petz M, Alfanz A, Gugerell A, Wittinger M, Gleiss A, Auner V, et al: Methylation status of TUSC3 is a prognostic factor in ovarian cancer. Cancer 119: 946-954, 2013

17. Zhao Y, Schetter AJ, Yang GB, Nguyen G, Mathé EA, Li P, Cai H, $\mathrm{Yu} \mathrm{L}$, Liu F, Hang D, et al: microRNA and inflammatory gene expression as prognostic marker for overall survival in esophageal squamous cell carcinoma. Int J Cancer 132: 2901-2909, 2013

18. Li Q, Yokoshi M, Okada H and Kawahara Y: The cleavage pattern of TDP-43 determines its rate of clearance and cytotoxicity. Nat Commun 6: 6183, 2015.

19. Yu X, Zhang K, Liu F, Zhang J, Zhai C, Cao L, Song X, Wang Y $\mathrm{Li}$ B, Sun $\mathrm{H}$ and Du J: Tumor suppressor candidate 3 as a novel predictor for lymph node metastasis in lung cancer patients. Oncol Lett 12: 5099-5105, 2016.

20. Gu Y, Pei X, Ren Y, Cai K, Guo K, Chen J, Qin W, Lin M, Wang Q, Tang N, et al: Oncogenic function of TUSC 3 in non-small cell lung cancer is associated with Hedgehog signalling pathway. Biochim Biophys Acta Mol Basis Dis 1863: 1749-1760, 2017.

21. Yuan J, Yu X, Wang A, Li Y, Liu F, Wang Y, Sun S, Bing X, Liu Y and Du J: Tumor suppressor candidate 3: A novel grading tool and predictor of clinical malignancy in human gliomas. Oncol Lett 15: 5655-5661, 2018

22. Duppel U, Woenckhaus M, Schulz C, Merk J and Dietmaier W: Quantitative detection of TUSC3 promoter methylation-a potential biomarker for prognosis in lung cancer. Oncol Lett 12: 3004-3012, 2016.
23. Bartel DP: MicroRNAs: Genomics, biogenesis, mechanism, and function. Cell 116: 281-297, 2004.

24. Hammond SM: An overview of microRNAs. Adv Drug Deliv Rev 87: 3-14, 2015.

25. Ghildiyal M and Zamore PD: Small silencing RNAs: An expanding universe. Nat Rev Genet 10: 94-108, 2009.

26. Soifer HS, Rossi JJ and Saetrom P: MicroRNAs in disease and potential therapeutic applications. Mol Ther 15: 2070-2079, 2017.

27. Krol J, Loedige I and Filipowicz W: The widespread regulation of microRNA biogenesis, function and decay. Nat Rev Genet 11: 597-610, 2010.

28. O'Connell RM, Rao DS, Chaudhuri AA and Baltimore D: Physiological and pathological roles for microRNAs in the immune system. Nat Rev Immunol 10: 111-122, 2010.

29. Qadir MI and Faheem A: miRNA: A diagnostic and therapeutic tool for pancreatic cancer. Crit Rev Eukaryot Gene Expr 27: 197-204, 2017.

30. Tutar Y: miRNA and cancer; computational and experimental approaches. Curr Pharm Biotechnol 15: 429, 2014.

31. Prado MSG, de Jesus ML, de Goes TC, Mendonça LSO and Kaneto CM: Downregulation of circulating miR-320a and target gene prediction in patients with diabetic retinopathy. BMC Res Notes 13: 155, 2020.

32. Zhang C, Yang H, Li Y, Huo P and Ma P: LNCRNA OIP5-AS1 regulates oxidative low-density lipoprotein-mediated endothelial cell injury via miR-320a/LOX1 axis. Mol Cell Biochem 467: 15-25, 2020.

33. Qin H, Liu J, Du ZH, Hu R, Yu YK and Wang QA: Circular RNA hsa_circ_0012673 facilitates lung cancer cell proliferation and invasion via miR-320a/LIMK18521 axis. Eur Rev Med Pharmacol Sci 24: 1841-1852, 2020.

34. Li M, Qu L, Chen F and Zhu X: Propofol upregulates miR-320a and reduces HMGB1 by downregulating ANRIL to inhibit PTC cell malignant behaviors. Pathol Res Pract 216: 152856, 2020.

35. Wang Y, Yang J, Chen P, Song Y, An W, Zhang H, Butegeleqi B and Yan J: MicroRNA-320a inhibits invasion and metastasis in osteosarcoma by targeting cytoplasmic polyadenylation element-binding protein 1. Cancer Med 9: 2833-2845, 2020.

36. Wu S, Chen S, Lin N and Yang J: Long non-coding RNA SUMO1P3 promotes hepatocellular carcinoma progression through activating Wnt/ $\beta$-catenin signalling pathway by targeting miR-320a. J Cell Mol Med 24: 3108-3116, 2020 .

37. Zhao JJ, Yang J, Lin J, Yao N, Zhu Y, Zheng J, Xu J, Cheng JQ, Lin JY and Ma X: Identification of miRNAs associated with tumorigenesis of retinoblastoma by miRNA microarray analysis. Childs Nerv Syst 25: 13-20, 2009.

38. Livak KJ and Schmittgen TD: Analysis of relative gene expression data using real-time quantitative PCR and the 2(-Delta Delta C(T)) method. Methods 25: 402-408, 2001.

39. Zhong Y, Zhao M, Yu Y, Li Q, Wang F, Wu P, Zhang W and Miao L: Prognostic value and therapeutic potential of the long noncoding RNA TP73-AS1 in cancers: A systematic review and meta-analysis. Sci Rep 10: 9053, 2020.

40. Morris LG and Chan TA: Therapeutic targeting of tumor suppressor genes. Cancer 121: 1357-1368, 2015.

41. Yang Y and Mei Q: miRNA signature identification of retinoblastoma and the correlations between differentially expressed miRNAs during retinoblastoma progression. Mol Vis 21: 1307-1317, 2015.

42. Castro-Magdonel BE, Orjuela M, Camacho J, García-Chéquer AJ, Cabrera-Muñoz L, Sadowinski-Pine S, Durán-Figueroa N, Orozco-Romero MJ, Velázquez-Wong AC, Hernández-Ángeles A, et al: miRNome landscape analysis reveals a 30 miRNA core in retinoblastoma. BMC Cancer 17: 458, 2017.

43. Svoronos AA, Engelman DM and Slack FJ: OncomiR or tumor suppressor? The duplicity of MicroRNAs in cancer. Cancer Res 76: 3666-3670, 2016.

44. Gao T, Deng M and Wang Q: MiRNA-320a inhibits trophoblast cell invasion by targeting estrogen-related receptor-gamma. J Obstet Gynaecol Res 44: 756-763, 2018.

45. Yong S, Yabin Y, Bing Z, Chuanrong Z, Dianhua G, Jianhuai Z, Weidong Y, Shuming W and Ling L: Reciprocal regulation of DGCR 5 and miR-320a affects the cellular malignant phenotype and 5-FU response in pancreatic ductal adenocarcinoma. Oncotarget 8 : 90868-90878, 2017.

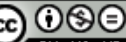

This work is licensed under a Creative Commons Attribution-NonCommercial-NoDerivatives 4.0 International (CC BY-NC-ND 4.0) License. 